\title{
Design and Simulation of a Rectangular E-Shaped Microstrip Patch Antenna for RFID based Intelligent Transportation
}

\author{
Asif Ali \\ Postgraduate student in Department of Telecommunication \\ Engineering \\ Mehran University of Engineering and Technology \\ Jamshoro, Pakistan \\ Nasrullah Pirzada \\ Assistant Professor in Department of Telecommunication \\ Engineering \\ Mehran University of Engineering and Technology \\ Jamshoro, Pakistan
}

\author{
Muhammad Moazzam Jawaid \\ Assistant Professor in Department of Computer System \\ Engineering \\ Mehran University of Engineering and Technology \\ Jamshoro, Pakistan \\ Sajjad Ali Memon \\ Assistant Professor in Department of Telecommunication \\ Engineering \\ Mehran University of Engineering and Technology \\ Jamshoro, Pakistan
}

\begin{abstract}
A low profile, rectangular E-shaped microstrip patch antenna is designed and proposed for radio-frequency identification (RFID) based intelligent transportation system (ITS) in this paper. The proposed antenna design aims to achieve high gain and low return loss at $0.96 \mathrm{GHz}$ as it is suitable for ultra-high frequency (UHF) RFID tags. The proposed antenna composed of a radiating patch on one side of the dielectric substrate and the ground plane on the other side, copper is used to produce the main radiator. The simulation of the proposed antenna is performed employing the high-frequency structure simulator (HFSS). The dielectric substrate used for the suggested antenna is an FR4 substrate with dielectric constant of 4.3 and height $1.5 \mathrm{~mm}$. The performance of the proposed antenna is measured in terms of gain, return loss, voltage standing wave ratio (VSWR), radiation pattern and the bandwidth. The antenna gain and the return loss of the suggested antenna at 0.96

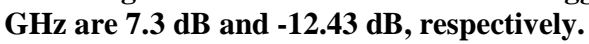

Keywords-E-shaped microstrip patch antenna; antenna gain; return loss; voltage standing wave ratio (VSWR); high-frequency structure simulator (HFSS)

\section{INTRODUCTION}

Presently, public transportation systems are an essential element of human lives. And it is a known fact that every year thousands of human lives are lost in the road accidents. However, road accidents can be mitigated by controlling the transportation systems intelligently using the technology, as every year millions of new vehicles hit the roads. Only in 2016, 77.31 million cars have been sold and this number has increased in 2017 by 1.28 million and counting [1]. Therefore, it is getting difficult to handle the transportation traffic using manual management systems. Thanks to the intelligent transportation systems (ITS), which proffer effectual solution for many transportation troubles as contrasted to the traditional solutions [2].
Electronic toll collection (ETC) systems are an excellent illustration of ITS applications that are employed right through the world and also brings significant advantages to the toll road users and the people at large, as contrasted to the conventional collection system for instance stop and pay at manned toll booths [3]. These ETC systems use ultra-high frequency (UHF) and radio-frequency identification (RFID) technology due to their fast reading and low-cost features. However, the effectiveness of this technology depends on the passive RFID tag reading by RFID reader antenna [4], [5]. The microstrip patch antenna is able to utilize thick substrates to meet the bandwidth demands of many potential applications [6]. We designed the E-shaped microstrip patch to evade impedance mismatches when our antenna placed at toll collection booth for reading the RFID tag [7]. Avoiding impedance mismatches direct the antenna radiate power along it's in a vehicle direction. At the higher frequency, the wide radiation beam has generated the superposition of the radiated signal and oppositely placed element on other side direction. The wide beam width is more suitable for some particular applications [8].

The organization of paper as follows: Section 2 discusses the existing work related to the antenna design for intelligent transport system based on RFID. Antenna designing configuration elaborated in Section 3. Section 4 defines the results analysis and discussion. At last, Section 5 concludes and recommends some future work.

\section{RELATED WORK}

The developing of transportation industry prompts to the traffic congestion and insist on proficient intelligent transportation. The intelligent transportation system is one the best solution to alleviate these problems from the society. ITS can be portrayed as an advanced system of computing, telecommunication industry advances the security, viable 
traffic management, and congestion. ITS is applicable for traffic monitoring and managing, toll taxing, parking, and communication between vehicles. The motivation of the work is getting from socio-economic demands and environmental needs. One major part of ITS is antenna design with appropriate materials and shapes sizes. Though, most of the antennas are designed on an unbending substrate which limits the space to align the antenna on vehicles with effective outcomes [9]-[11] Therefore, many types of the antennas have been proposed and designed for the UHF RFID systems in the literature [12]-[16]. However, these proposed antenna designs are specific to certain applications. The microstrip antenna is one of the popular antennas that is used in many applications. Besides many advantages (such as less complex, lightweight, easy to manufacture and cheap) offered by microstrip antennas, they tend to have a larger size in the ultra high frequency (UHF) range [17], [18]. This paper proposed an antenna design for RFID reader that can be employed at the toll plazas to read the passive RFID tags efficiently. The proposed antenna is compact and low profile, rectangular Eshaped microstrip patch that aims to achieve high gain and low return loss at $0.96 \mathrm{GHz}$. The RFID tag comprises an antenna and semiconductor chip containing some information related the vehicle identification. The chip transmits the radio signal through RFID reader, the tag need the active power support all the time to read the information [19]. Unfortunately, authors fail to activate the RFID reader all the time. The innovative expertise will help to find the fresh solutions to the existing system problems like traffic congestion, vehicle identification, monitoring of observance to traffic rules and aware about the accident for instant management [11]. In this paper, the proposed antenna, wide axial ratio bandwidth is achieved by using coupling feeding mechanism. It is observed that the back lobes are dominant to reduce the antenna gain and performance [20]. The phased array radar with imaging system used here, the millimeter wave antenna is employed for the short-range communication of the application of the vehicle [21]. The literature review presents some limited range of applications of the antenna for ITS in tolling. It is noted that the existing work has discussed the antennas for ITS with larger in size and provided results are not up to mark can be utilized for tolling.

The aim of this paper is more especially to design a compact size antenna with better and efficient results. We have designed the E-shaped microstrip patch antenna for the intelligent transportation systems application.

\section{PROPOSED ANTENNA DESIGN}

Transmission-line model is used for analyzing the suggested E-shaped microstrip patch antenna design [22]. The design of the suggested E-shaped microstrip patch antenna is illustrated in Fig. 1, where $W_{p}$ and $L_{p}$ represents the patch width and patch length respectively, therefore, the size of the metallic radiating patch of the proposed antenna is $W_{p} \times L_{p}$.
Furthermore, $W_{s}, L_{s}$ and $h$ represents the width, length, and height of dielectric substrate respectively, therefore, the size of the dielectric substrate of the suggested antenna is $W_{s} \times L_{s} \times h$. Moreover, $W_{f}, L_{f}, g$ and $y_{o}$ represents the feed line width, feedline length, inset gap and inset length, respectively. The proposed antenna operating frequency $f_{o}$, the dielectric constant of the substrate $\epsilon_{r}$ and the height (thickness) of the dielectric substrate are $960 \mathrm{MHZ}, 4.3$ and $1.5 \mathrm{~mm}$ respectively. As the proposed antenna is analyzed using transmission-line model, so $W_{p}$ and $L_{p}$ can be calculated using following equations, respectively [5].

$$
\begin{gathered}
W_{p}=\frac{c}{2 f_{o}}\left(\frac{2}{\epsilon_{r}+1}\right)^{\frac{1}{2}} \\
L_{p}=\frac{1}{2 f_{o} \sqrt{\epsilon_{\text {reff }} \mu_{o} \epsilon_{o}}}-2 \Delta L
\end{gathered}
$$

Where $c$ is the speed of the light, $\in_{\text {reff }}$ is the effective dielectric constant, $\mu_{o}$ is permeability of the free space and $\Delta L$ is extension length. The extension length $\Delta L$ and the effective dielectric constant $\in_{\text {reff }}$ can be calculated using following equations, respectively.

$$
\begin{gathered}
\Delta L=0.412 h\left[\left(\frac{\epsilon_{\text {reff }}+0.3}{\epsilon_{\text {reff }}-0.258}\right)\left(\frac{\frac{W_{p}}{h}+0.264}{\frac{W_{p}}{h}+0.813}\right)\right] \\
\in_{\text {reff }}=\frac{\epsilon_{r}+1}{2}+\frac{\epsilon_{r}-1}{2}\left(1+\frac{12 h}{W_{p}}\right)^{\frac{-1}{2}}
\end{gathered}
$$

The proposed E-shaped microstrip patch antenna is simulated via high-frequency structure simulator (HFSS) software and the FR4 substrate is used as the dielectric material having a loss tangent of 0.025. The suggested Eshaped microstrip patch antenna is fed by the input impedance $Z_{o}$ of $50 \Omega$.

\section{Methodology}

As mentioned in Section III that the proposed antenna is simulated in HFSS, for that we need to design the proposed antenna with the specific values in the said simulator. The specific values can be referred as simulation parameters and some of these values can be calculated from the equations discussed in Section III. After calculating the specific values, the design of the proposed antenna can be modeled in the HFSS simulator that may look like as shown in Fig. 2. 


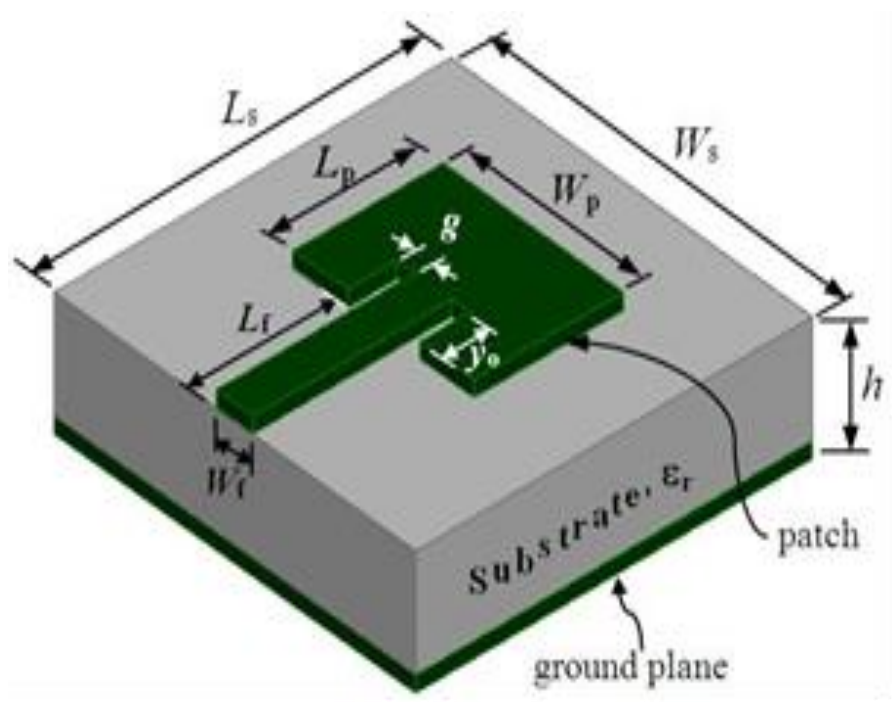

Fig. 1. Proposed design of the E-shaped microstrip patch antenna.

\section{SimUlation RESUlts AND DisCUSSION}

The proposed E-shaped microstrip patch antenna is simulated in HFSS simulator using simulation parameters listed in Table I. The configuration of the suggested antenna in HFSS simulator is illustrated in Fig. 2.

TABLE I. SIMULATION PARAMETERS USED IN HFSS SIMULATION

\begin{tabular}{|l|l|l|}
\hline Parameter & Symbol & Value \\
\hline The dielectric constant of the substrate & $\in_{r}$ & 4.3 \\
\hline Inset Gap & $g$ & $3 \mathrm{~mm}$ \\
\hline Inset length & $y_{o}$ & $10 \mathrm{~mm}$ \\
\hline Substrate Thickness & $h$ & $1.5 \mathrm{~mm}$ \\
\hline Operating frequency & $f_{o}$ & $0.96 \mathrm{GHz}$ \\
\hline Patch Dimension Along $\mathrm{x}$ & $W_{p}$ & $39 \mathrm{~mm}$ \\
\hline Patch Dimension Along y & $L_{p}$ & $30 \mathrm{~mm}$ \\
\hline Feed Width & $W_{f}$ & $5 \mathrm{~mm}$ \\
\hline Feed Length & $L_{f}$ & $20 \mathrm{~mm}$ \\
\hline Substrate Dimension Along $\mathrm{x}$ & $W_{s}$ & $65 \mathrm{~mm}$ \\
\hline Substrate Dimension Along y & $L_{s}$ & $56 \mathrm{~mm}$ \\
\hline Input impedance & $Z_{o}$ & $50 \Omega$ \\
\hline
\end{tabular}

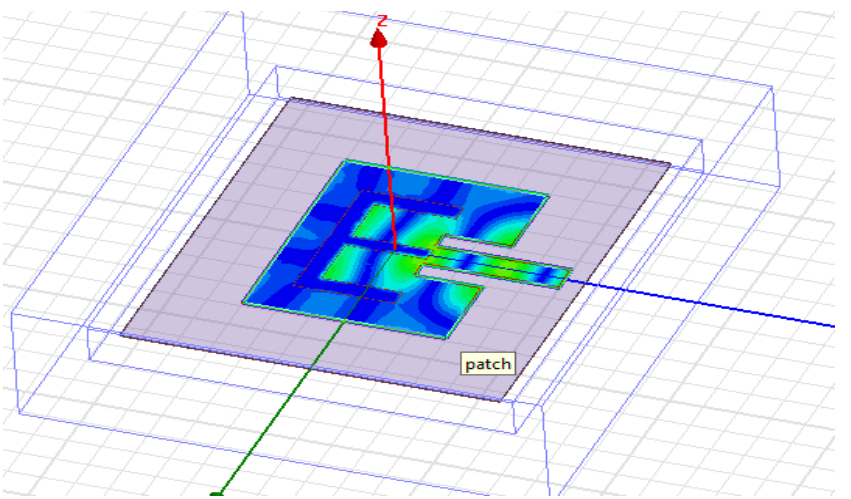

Fig. 2. Proposed E-shaped microstrip antenna in HFSS simulator.

The antenna is characterized by its parameters mentioned already in the previous section. Simulation outcomes are presented in this segment. The simulated return loss of the suggested microstrip antenna is illustrated in Fig. 3. The proposed antenna has a minimum value of $-12.38 \mathrm{~dB}$ of return loss obtained at $0.96 \mathrm{GHz}$. Fig. 4 illustrates the 3D gain of the suggested microstrip antenna where the peak gain of $7.3 \mathrm{~dB}$ is achieved at the frequency of $0.96 \mathrm{GHz}$. The directivity of the antenna is in the X-axis direction and the gain is $5.5 \mathrm{~dB}$. The directivity of the suggested E-shaped microstrip patch antenna is illustrated in Fig. 5. The values obtained from the simulation are suitable for the ITS application. Fig. 6 illustrates the radiation pattern the of suggested microstrip patch antenna. It shows the horizontal and vertical half powerbeam width. Voltage standing wave ratio (VSWR) value for the suggested microstrip antenna is found to be 0.67 , and the simulated input impedance is $48.5 \Omega$, which is not much less than the set input impedance. That translates that the proposed microstrip antenna has low losses.

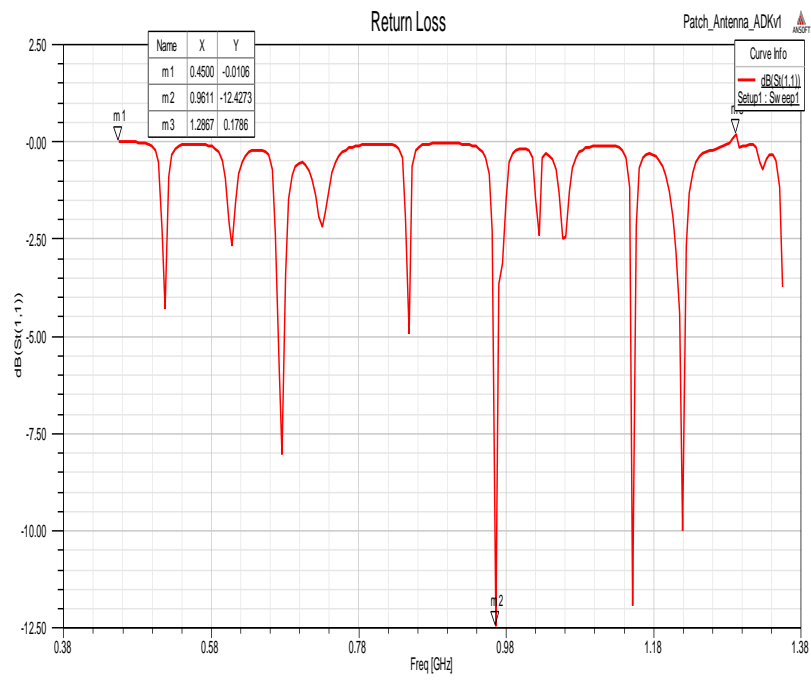

Fig. 3. Proposed antenna simulated return loss.

TABLE II. COMPARING THE RESULTS OF DIFFERENT WORKS

\begin{tabular}{|l|l|l|l|l|l|l|}
\hline Papers & Operating frequency & Size & Return loss & Gain in dB & VSWR & Impedance \\
\hline Our paper & $0.96 \mathrm{GHz}$ & $65 X 56 \mathrm{~mm}$ & $-12.38 \mathrm{~dB}$ & $7.3 \mathrm{~dB}$ & 0.67 & $48.5 \Omega$ \\
\hline$[8]$ & $15 \mathrm{GHz}$ & $6.4 X 8.5 \mathrm{~mm}$ & $-10 \mathrm{~dB}$ & $9.6 \mathrm{~dB}$ & 0.57 & $50 \Omega$ \\
\hline$[6]$ & $2.25 \mathrm{GHz}$ & $55.1 \times 49 \mathrm{~mm}$ & $-12.5 \mathrm{~dB}$ & $9.76 \mathrm{~dB}$ & 0.98 \\
\hline$[20]$ & $2.49 \mathrm{GHz}$ & $30 \times 30 \mathrm{~mm}$ & $-15 \mathrm{~dB}$ & $4.6 \mathrm{~dB}$ & 1.8 & $50 \Omega$ \\
\hline
\end{tabular}



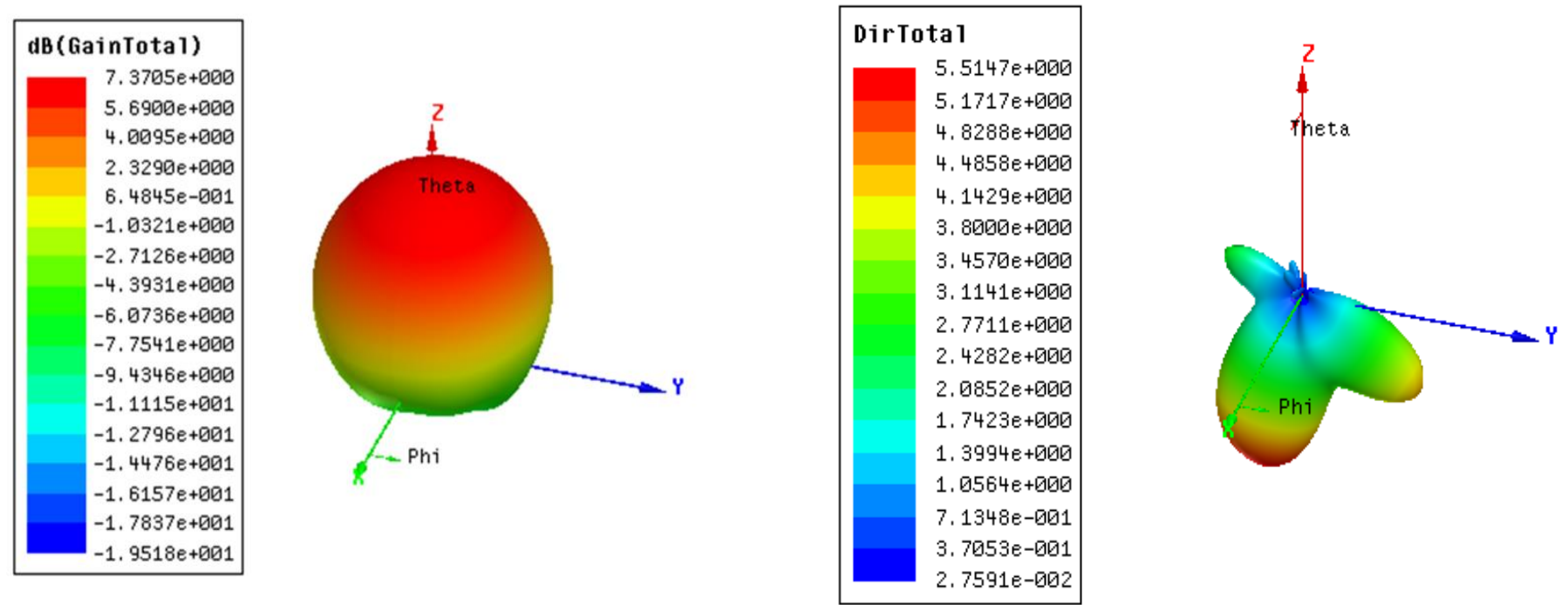

Fig. 4. Proposed antenna simulated gain.

Fig. 5. Proposed antenna simulated directivity.
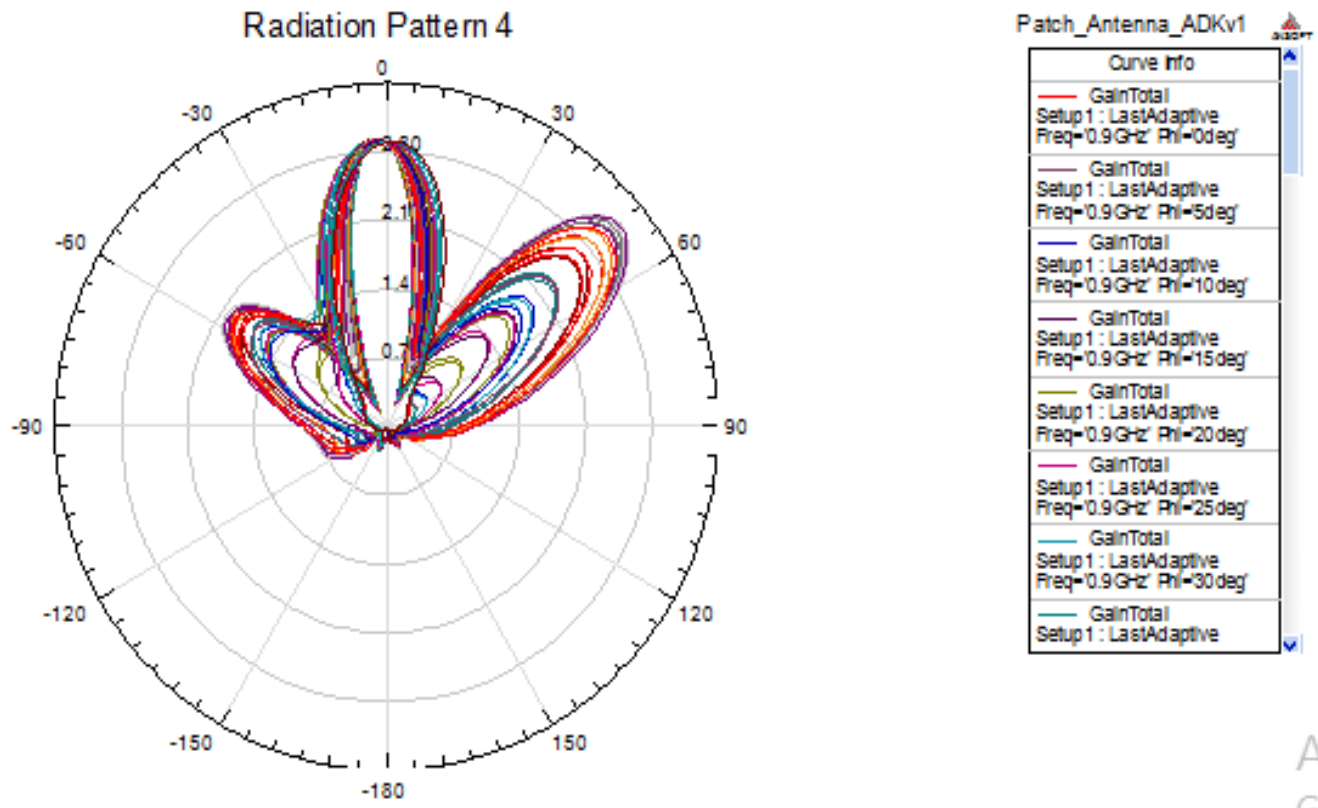

Fig. 6. Proposed antenna simulated radiation pattern.

Table II compares the results of the proposed antennas with other works [8], [6], [20]. As the operating frequency increases the antenna size will decrease as can be seen from the table. Therefore, the antenna size of the proposed antenna is relatively small compared to [8], [6] and [20] as the operating frequency of the proposed antenna is comparatively higher than the other works. Similarly, the return loss of the proposed antenna is better than the [6] and [20], while slightly higher than [8]. The gain of an antenna will increase as the frequency increase [20]. Therefore, the gain of the proposed antenna is relatively higher than [8], [6] and [20]. Similarly, the VSWR and impedance matching of the proposed antenna is better than the [8], [6] and [20] as seen in Table II.

\section{CONCLUSION}

In this paper, the proposed antenna of $65 \times 56 \mathrm{~mm}^{2}$ size simulated in HFSS v13 on FR4 substrate 4.3 dielectric constants with operating frequency of $0.96 \mathrm{GHz}$ is discussed with accomplishing the antenna suite for intelligent transport systems. This proposed antenna suitably improves the antenna with high gain and directivity. In vehicles, antenna orientation is not dependent on anything, the radiation pattern of ESlotted patch antenna provides omnidirectional pattern can accommodate the tolling traffic in an effective manner. This model yields the effective results in terms of gain $7.3 \mathrm{~dB}$; directivity $5.5 \mathrm{~dB}$ with better impedance matching, VSWR of 0.67 was achieved. The simulated radiation efficiency of $70 \%$ 
along with impedance bandwidth of $33 \mathrm{MHz}$ has been revealed. This antenna can be investigated on a different range of wireless applications and vehicular applications. It is observed that due to its higher beam width at $70^{\circ}$ with a circularly polarized response. The benefit of the substrate of low dielectric is that it is favored for maximum radiation. For the reason that of directivity and wide radiation pattern, the rectangular patch antenna is preferred. Proposed configurations for E-shaped microstrip patch antenna meet specifications for highway toll collection or vehicle fleet identification applications.

\section{REFERENCES}

[1] A. J. Al-Dweik, M. Mayhew, R. Muresan, S. M. Ali, and A. Shami, "Using Technology to Make Roads Safer: Adaptive Speed Limits for an Intelligent Transportation System," IEEE Veh. Technol. Mag., vol. 12, no. 1, pp. 39-47, 2017.

[2] K. Sjoberg, P. Andres, T. Buburuzan, and A. Brakemeier, "Cooperative Intelligent Transport Systems in Europe: Current Deployment Status and Outlook," IEEE Veh. Technol. Mag., vol. 12, no. 2, pp. 89-97, 2017.

[3] J. Odeck and M. Welde, "Economic evaluation of intelligent transportation systems strategies: the case of the Oslo toll cordon," IET Intell. Transp. Syst., vol. 4, no. 3, p. 221, 2010.

[4] Y. Yao, Y. Liang, J. Yu, and X. Chen, "Design of a multi-polarized RFID reader antenna for UHF near-field applications," IEEE Trans. Antennas Propag., vol. 65, no. 7, pp. 3344-3351, 2017.

[5] A. Farswan, A. K. Gautam, B. K. Kanaujia, and K. Rambabu, "Design of Koch Fractal Circularly Polarized Antenna for Handheld UHF RFID Reader Applications," IEEE Trans. Antennas Propag., vol. 64, no. 2, pp. 771-775, 2016.

[6] J. M. Kovitz, H. Rajagopalan, and Y. Rahmat-Samii, "Circularly polarised half E-shaped patch antenna: a compact and fabricationfriendly design," vol. 10, pp. 932-938, 2016.

[7] C. Qi, P. Hillyard, A. Al-Hussein, N. Patwari, G. D. Durgin, and A. Tagless, "On-Wall, Wide Bandwidth E-Shaped Patch Antenna for Improved Whole-Home Radio Tomography," vol. 1, no. 1, pp. 22-31, 2017.

[8] H. Jin, K. Chin, W. Che, S. Member, and C. Chang, "A Broadband Patch Antenna Array With Planar Differential L-Shaped Feeding Structures," vol. 14, pp. 127-130, 2015.

[9] V. Van Yem et al., "Novel High Gain and Broadband CPW-Fed Antennas With EBG for ITS Applications,” pp. 451-456, 2013.

[10] T. Mondal, S. Samanta, R. Ghatak, and S. R. Bhadra Chaudhuri, "A novel circularly polarized dsrc band square microstrip antenna using the minkowski fractal structure for vehicular communication," 2014 IEEE International Conference on Vehicular Electronics and Safety, Hyderabad, 2014, pp. 141-146.

[11] D. A. Jagtap and V. U. Deshmukh, "Review Paper on Design of a Coplanar Integrated Microstrip Antenna for ITS Applications," pp. 1261-1264, 2017.

[12] A. Larionov, R. Ivanov, and V. Vishnevsky, "UHF RFID in Automatic Vehicle Identification: Analysis and Simulation," IEEE J. Radio Freq. Identif., vol. 1, no. 1, pp. 1-1, 2017.

[13] H. Salah, H. A. Ahmed, J. Robert, and A. Heuberger, "Multi-Antenna UHF RFID Reader Utilizing Stimulated Rate Tolerance," vol. 1, no. 2, pp. 124-134, 2017.

[14] P. Forouzannezhad, A. Jafargholi, and A. Jahanbakhshi, "Multiband compact antenna for near-field and far-field RFID and wireless portable applications," IET Microwaves, Antennas Propag., vol. 11, no. 4, pp. 535-541, 2017.

[15] S. Maddio, "A Compact Circularly Polarized Antenna for 5. $8 \mathrm{GHz}$ Intelligent Transportation System," vol. 1225, no. c, pp. 8-11, 2016.

[16] R. Caso, A. Michel, M. Rodriguez-Pino, and P. Nepa, "Dual-band UHFRFID/WLAN circularly polarized antenna for portable RFID readers," IEEE Trans. Antennas Propag., vol. 62, no. 5, pp. 2822-2826, 2014.

[17] K. Fan, Z. Hao, S. Member, and Q. Yuan, "A Low-Profile Wideband Substrate-Integrated Antenna for the Q-LINKPAN Applications," vol. 65, no. 11, pp. 5667-5676, 2017.

[18] Dahri, F. A, Soomro R. A, Memon Z. A "Design of Wearable Microstrip Yagi Array Antenna aimed for Telemedicine Applications", Academic Journal of Management Science (AJMS), Vol. 5, No.2, pp 4552, 2017.

[19] I. Tabakh, M. Jorio, N. El Amrani El Idrissi, and T. Mazri, "Design and simulation of an optimized slotted patch antenna for RFID reader applications," 2016 International Conference on Information Technology for Organizations Development (IT4OD), Fez, 2016, pp. 16.

[20] T. Mondal, S. Maity, R. Ghatak, S. Ranjan, and B. Chaudhuri, "Compact Circularly Polarized Wide Beam Width Fern Fractal Shaped Microstrip Antenna for Vehicular Communication," vol. xx, no. xx, pp. $1-9,2018$

[21] N. Kishore, G. Upadhyay, A. Prakash, and V. S. Tripathi, "Millimeter Wave Antenna for Intelligent Transportation Systems Application," vol. 17, no. 1, pp. 171-178, 2018.

[22] H. Pues and a. van de Capelle, "Accurate transmission-line model for the rectangular microstrip antenna," IEE Proc. H Microwaves, Opt. Antennas, vol. 131, no. June, p. 334, 1984. 